\title{
Increased body mass index per se is not a predictor of difficult laryngoscopy
}

\author{
[Un indice de masse corporelle élevé n'est pas, en soi, un prédicteur de
}

laryngoscopie difficile]

Tiberiu Ezri MD, ${ }^{*}$ Beniamin Medalion MD, $\uparrow$ Marian Weisenberg MD, ${ }^{*}$ Peter Szmuk MD, $\mathfrak{S}$ R. David Warters MD, $\$$ Ilan Charuzi MD

Purpose: We investigated the association between morbid obesity and difficult laryngoscopy (DL).

Methods: In a prospective, controlled study we evaluated the impact of different variables on the prediction of DL in 200 morbidly obese (study group-SG), and I,272 non-obese (control group-CG) patients undergoing elective surgery. Variables assessed included age, sex, body mass index (BMI), protruding, loose, and missing upper teeth, thyro-mental distance, temporo-mandibular joint (TMJ) function, neck extension, and Mallampati class. A Cormack grade III or IV was considered DL.

Results: The SG patients were younger $(P<0.000)$, there were more females in the SG $(P<0.000)$ and more in the SG had teeth problems $(P=0.026)$. More patients in the SG (I0\% vs I\%), had obstructive sleep apnea $(P<0.00 \mathrm{I})$ with $90 \%$ of them in the SG having a grade III laryngoscopy. High BMI did not affect the laryngoscopy difficulty $(P=0.56)$. Multivariable regression analysis revealed that morbid obesity, increased age, male sex, pathology of TMJ, and higher Mallampati class, were independent predictors of $\mathrm{DL}$. When interaction between the predictors and the group was added to the multivariable model, the SG was no longer a predictor by itself, rather its association with abnormal upper teeth turned to be significant for prediction of DL.

Conclusions: Increased age, male sex, TMJ pathology, Mallampati 3 and 4, a history of obstructive sleep apnea and abnormal upper teeth were associated with a higher incidence of DL. The magnitude of BMI had no influence on difficulty with laryngoscopy.
Objectif : Nous avons examiné le lien entre l'obésité morbide et la laryngoscopie difficile (LD).

Méthode : Dans une étude prospective et contrôlée, nous avons évalué l'impact de différentes variables sur la prédiction de LD chez 200 patients présentant une obésité morbide (groupe expérimental - GE) et I 272 patients non obèses (groupe témoin - GT) devant subir une intervention chirurgicale réglée. Les variables évaluées ont été : l'âge, le sexe, l'indice de masse corporelle (IMC), la protrusion, la mobilité et l'absence de dents supérieures, la distance thyromentonnière, la compétence de l'articulation temporo-mandibulaire (ATM), l'extension du cou et la classification de Mallampati. Une cote III ou IV de Cormack a été considérée comme une LD.

Résultats : Les patients du GE étaient plus jeunes $(P<0,000)$, comprenaient plus de femmes $(P<0,000)$ et présentaient plus de problèmes dentaires $(P=0,026)$. Un plus grand nombre de patients du GE (10 \% vs I \%) avaient une apnée du sommeil d'origine obstructive $(P<0,00$ I) dont $90 \%$ présentaient une laryngoscopie de classe III. Un IMC élevé n'a pas eu d'influence sur la laryngoscopie difficile $(P=0,56)$. Une analyse de régression multivariable a révélé que l'obésité morbide, l'âge avancé, le sexe mâle, une pathologie de l'ATM et une cote de Mallampati plus élevée ont été des prédicteurs indépendants de LD. Si on ajoute l'interaction entre les prédicteurs et le groupe au modèle multivariable, le GE n'est plus un prédicteur en lui-même, quoique son association avec une dentition supérieure anormale apparaisse significative pour prédire une LD.

Conclusion : Le vieillissement, le sexe masculin, une pathologie de I'ATM, une classe 3 ou 4 de Mallampati, des antécédents d'apnée du sommeil d'origine obstructive et des anomalies de la dentition supérieure ont été associés à une plus grande incidence de LD. Un IMC plus élevé n'a pas d'influence sur les difficultés laryngoscopiques.

From the Departments of Anesthesia, * Cardiothoracic Surgery, $\dagger$ and General Surgery “B”, $\ddagger$ Wolfson Medical Center, Holon, Affiliated with Sackler School of Medicine, Tel Aviv, Israel; and the Department of Anesthesiology, $\$$ University of Texas Medical School at Houston, Texas, USA.

Address correspondence to: Dr. Tiberiu Ezri, Director, Department of Anesthesia, Wolfson Medical Center, Holon, Israel. Phone: 972-35028229; Fax: 972-8-9475188; E-mail: tezri@netvision.net.il

Accepted for publication June 10, 2002.

Revision accepted October 17, 2002. 
$\mathrm{T}$

HE ability of a specific test to predict a difficult laryngoscopy (DL) is decreased by the variability of its definition, ${ }^{1,2}$ and the inter-observer variability of performing a specific test. ${ }^{3}$ Data concerning the impact of obesity in the prediction of a DL are also controversial. ${ }^{4,5}$ The purpose of our study was to evaluate the impact of specific factors in predicting a DL in morbidly obese patients undergoing elective surgery.

\section{Methods}

This study was approved by the hospital Ethics Committee, and written informed consent was obtained from each patient. During a three-month period, all consecutive patients older than $18 \mathrm{yr}$ of age, who arrived in the preoperative holding area for elective surgery, were enrolled in this controlled, prospective study. Patients scheduled for regional anesthesia and general anesthesia without endotracheal intubation, or patients with upper airway pathology (i.e., maxillo-facial fractures, tumours, etc), cervical spine fractures, full stomach, hiatal hernia, gastroesophageal reflux, pregnancy, and patients with a history of DL/intubation were excluded from the study. All preoperative airway evaluations were performed by a single attending anesthesiologist. The variables assessed included:

- The presence of a history of obstructive sleep apnea (OSA) which was diagnosed based on the results of polysomnography and defined as epochs of apnea that last ten seconds or more and occur at least five times per hour. ${ }^{6}$

- Abnormal upper teeth: loose upper teeth, protruding upper teeth, and partially missing upper incisors and/or canines.

- Impaired temporo-mandibular joint (TMJ) mobility: inter-incisor gap less than $3 \mathrm{~cm}$, inability to move the lower teeth in front of the upper teeth.

- Thyro-mental distance less than $6 \mathrm{~cm}$.

- Limited neck movements: inability to extend and flex the neck to a range around $90 .^{7}$

- The back of the mouth view was assessed with the modified Mallampati scale: ${ }^{8}$ classes 3 and 4 were considered predictors of DL.

All the laryngoscopies were performed in a standardized "sniffing" position, ${ }^{9}$ with a size 3 Macintosh blade and the trachea was intubated with a styletted endotracheal tube. The laryngoscopy was performed and its grade was assessed by one of the four attending anesthesiologists, authors of the article (TE, MW, PS and RDW) each having an experience of over 15 years in anesthesiology. The laryngoscopy view was graded according to Cormack and Lehane's grading scale. ${ }^{1}$ No external laryngeal pressure was applied for grading of laryngoscopic view. DL was defined as grade III or IV laryngoscopy. With a grade III view, a 15 Ch gum elastic bougie (Sims Portex, Hythe Kent, England) was inserted underneath the epiglottis and the endotracheal tube was threaded into the trachea. If intubation was unsuccessful (failed) after three attempts, the patient was awakened and the procedure cancelled. Body mass index (BMI) was calculated from the following formula: ${ }^{10}$ BMI $=$ weight $\times$ height $^{-2}$ Patients with a BMI $>35 \mathrm{~kg} \cdot \mathrm{m}^{-2}$ were considered morbidly obese. ${ }^{11}$ Patients were allocated to two groups: the study group (SG) comprised morbidly obese patients undergoing laparoscopic weight reduction surgery (LapBand).

This group was subdivided into patients with a BMI 35-50 and BMI > 50. The control group (CG) included patients with a BMI $<35$ who underwent laparoscopic abdominal procedures (cholecystectomy, ventral and inguinal hernia repair, etc.).

No preoperative medication was administered.

Following five minutes of preoxygenation, anesthesia was induced with fentanyl $\left(1 \mu \mathrm{g} \cdot \mathrm{kg}^{-1}\right)$, thiopental $\left(3 \mathrm{mg} \cdot \mathrm{kg}^{-1}\right)$, and succinylcholine $\left(1 \mathrm{mg} \cdot \mathrm{kg}^{-1}\right)$ for facilitation of endotracheal intubation. Laryngoscopy was performed with full muscle relaxation (no twitches recorded on the ulnar nerve stimulator). Monitoring consisted of electrocardiogram, pulse oximetry, capnography, non-invasive blood pressure and temperature measurements.

\section{Statistical analysis}

Continuous variables are expressed as mean \pm standard deviation. Non-continuous variables are expressed as number of occurrences and percentage. For univariate analysis, the two-tail students t test was employed for continuous variables and Chi-square or Fisher exact test, as appropriate, for non-continuous variables. Multivariable logistic regression was used, with and without variable interactions, to identify independent predictors of DL. Statistical significance was defined as $P<$ 0.05 . We assessed the interaction between different variables with the study group (considered itself a variable) to reveal their combined effects as predictors of DL.

\section{Results}

A total of 200 morbidly obese and 1,272 non-obese patients were enrolled in the study.

Demographic data and preintubation variables are depicted in Table I. Patients in the SG, were younger, had a higher BMI and were mainly females. There were 
TABLE I Demographic and preintubation variables

\begin{tabular}{llll}
\hline & Study & Control & $P$ \\
\hline Age $(\mathrm{yr})$ & $37.4 \pm 9.9$ & $45.3 \pm 16.1$ & 0.000 \\
BMI $\left(\mathrm{kg} \cdot \mathrm{m}^{-2}\right)$ & $44 \pm 6.5$ & $26.7 \pm 3.9$ & 0.000 \\
Female & $146(73)$ & $578(45.4)$ & 0.000 \\
History of OSA & $20(10)$ & $6(0.5)$ & 0.001 \\
Abnormal upper teeth & $8(4)$ & $14(1.1)$ & 0.026 \\
Impaired TMJ & $2(1)$ & $18(1.4)$ & 0.74 \\
TMD < 6 cm & $42(21)$ & $188(14.8)$ & 0.11 \\
Limited neck movement & $16(8)$ & $174(13.7)$ & 0.12 \\
Mallampati class & 0.000 & & \\
1 & $50(25)$ & $276(21.7)$ & \\
2 & $104(52)$ & $572(45)$ & \\
3 & $34(17)$ & $410(32.2)$ & \\
4 & $12(6)$ & $14(1.1)$ & \\
Laryngoscopy grade & & & \\
I & $108(54)$ & $582(45.8)$ & 0.16 \\
II & $68(34)$ & $562(44.2)$ & \\
III & $24(12)$ & $128(10)$ & \\
IV & 0 & 0 & \\
\hline
\end{tabular}

Continuous variables are presented as mean \pm standard deviation, non-continuous variables are presented as number of occurrences and (percentage). $\mathrm{BMI}=$ body mass index; $\mathrm{TMJ}=$ temporomandibular joint; TMD = thyro-mental distance; OSA = obstructive sleep apnea.

more patients with abnormal upper teeth in the SG. Although more patients in CG had Mallampati class 3, more patients in SG had class 4 . The distribution of measured variables according to difficulty of intubation (laryngoscopy grade 3 or 4 vs 1 or 2 ) is presented in Table II. None of the patients had a grade IV laryngoscopy. Grade III occurred in $12 \%$ in SG and 10.1\% in CG. Twenty patients (10\%) in the SG revealed a history of OSA (16 had mild and four moderate OSA). Of these, 18 had a grade III laryngoscopy, all of them were males. Only six in the control group had a history of mild OSA $(P<0.001)$, all of them were males. Two of the six had a grade III laryngoscopy.

Those who had DL were older, were more likely to have abnormal upper teeth, TMJ dysfunction, TMD < $6 \mathrm{~cm}$, limited neck extension and higher Mallampati class.

A multivariable logistic regression analysis with a laryngoscopy grade 3 or 4 as end point, identified older age, male gender, TMJ dysfunction, higher Mallampati class and being member of the $S G$, as independent predictors of DL. When interactions between the predictors and the group were added as new variables to the model, the SG was no longer a predictor by itself, but the interaction between morbid obesity and abnormal upper teeth was a predictor of DL (Table III).
TABLE II Variables according to laryngoscopy difficulty univariate analysis

\begin{tabular}{llll}
\hline & $\begin{array}{l}\text { Laryngoscopy } \\
\text { grade } \geq I I I \\
n=152\end{array}$ & $\begin{array}{l}\text { Laryngoscopy } \\
\text { grade }<I I I \\
n=1,320\end{array}$ & $P$ \\
\hline Age $(\mathrm{yr})$ & $50.6 \pm 17.5$ & $43.5 \pm 15.2$ & 0.000 \\
BMI $\left(\mathrm{kg} \cdot \mathrm{m}^{-2}\right)$ & $29.55 \pm 7.6$ & $29 \pm 7.3$ & 0.56 \\
Female & $54(35.5)$ & $670(50.8)$ & 0.000 \\
OSA & $20(77)$ & $6(23)$ & 0.001 \\
Abnormal upper teeth & $6(3.9)$ & $16(1.2)$ & 0.06 \\
Impaired TMJ & $12(7.9)$ & $8(0.6)$ & 0.000 \\
TMD $<$ cm & $46(30.3)$ & $184(13.9)$ & 0.000 \\
Limited neck movement & $34(22.4)$ & $156(11.8)$ & 0.009 \\
Mallampati scale & 0.000 & & \\
1 & $16(10.5)$ & $310(23.5)$ & \\
2 & $20(13.2)$ & $656(49.7)$ & \\
3 & $100(65.8)$ & $344(26.1)$ & \\
4 & $16(10.5)$ & $10(0.7)$ & \\
Study group & $24(15.8)$ & $176(13.3)$ & 0.55 \\
\hline
\end{tabular}

Continuous variables are presented as mean \pm standard deviation, non-continuous variables are presented as number of occurrences and (percentage). $\mathrm{BMI}=$ body mass index; $\mathrm{TMJ}=$ temporomandibular joint; TMD = thyro-mental distance; OSA = obstructive sleep apnea.

Intubation failed in $1 \%$ in SG. Surgery was postponed after three unsuccessful attempts. The two patients were intubated fibreoptically the next day. Two patients in CG had their trachea intubated at the third attempt with the gum elastic bougie and external laryngeal pressure applied to facilitate the laryngoscopic view.

\section{Discussion}

Obesity has been found to be a risk factor for difficult intubation, ${ }^{4,12}$ yet, Meyer ${ }^{13}$ and Bond $^{5}$ failed to demonstrate a higher occurrence of difficult intubation in morbidly obese patients. Meyer ${ }^{13}$ had shown that intubation difficulty in 400 morbidly obese patients was similar to that of non-obese patients.

A body weight over $95 \mathrm{~kg}$, was considered a risk factor for difficult intubation by Wilson. ${ }^{14}$ However, the patient's height was not recorded, so a tall patient could have easily been confounded with an obese patient just on a weight basis. On the contrary, Bond ${ }^{5}$ evaluated the laryngoscopic view according to the patients' BMI. He examined 26 obese (12 morbidly obese) patients and 14 non-obese patients. As in the present study, he found no association between BMI and laryngoscopic view. The incidence of DL was $7.5 \%$. Of those with a DL, two had a BMI $<25$ and one a BMI of 36. Compared to Bond's study, both 
TABLE III Independent predictors for difficult laryngoscopy multivariable analysis

\begin{tabular}{|c|c|c|}
\hline & $\begin{array}{l}\text { Odd ratio } \\
\text { (95\% confidence } \\
\text { interval) }\end{array}$ & $P$ \\
\hline \multicolumn{3}{|l|}{ Without interaction variable } \\
\hline Older age & $1.03(1-1.04)$ & 0.002 \\
\hline Male & $1.99(1.14-3.45)$ & 0.014 \\
\hline Pathological TMJ & $22.3(3.6-136.6)$ & 0.000 \\
\hline Higher Mallampati grade & $4.1(2.7-6.15)$ & 0.000 \\
\hline Being in the study group & $2.2(1.03-4.76)$ & 0.04 \\
\hline \multicolumn{3}{|c|}{ With group as an interaction variable } \\
\hline Older age & $1.02(1.006-1.04)$ & 0.006 \\
\hline Male & $1.89(1.09-3.26)$ & 0.02 \\
\hline Pathological TMJ & $21.5(3.36-137.9)$ & 0.001 \\
\hline History of OSA & $10.6(4.7-19.8)$ & 0.001 \\
\hline Higher Mallampati grade & $4.2(2.8-6.4)$ & 0.000 \\
\hline Study group and abnormal teeth & $11.4(1.06-123)$ & 0.04 \\
\hline
\end{tabular}

$\mathrm{TMJ}=$ temporo-mandibular joint; OSA = obstructive sleep apnea.

our control and study groups comprised a much larger and uniform patient population. All our study group patients were morbidly obese and underwent the same surgical procedure. We observed that even a BMI > 50 is not associated with DL.

We also analyzed the impact of other patients' characteristics on the ease of laryngoscopy. Impaired TMJ seemed to be the strongest independent predictor of DL, with 12 out of the 20 patients with TMJ problems, having a grade III laryngoscopy (odd ratio 22.3 $-P<0.000)$.

Older age, male sex, TMJ pathology and higher Mallampati classes were found to be independent predictors of DL in both groups by multivariable regression analysis. This is in concordance with Rose et al.'s ${ }^{15}$ data published in 18,205 patients showing that intubation difficulty increases in males and with age. The finding that airway problems are more frequent in males and in older patients is reinforced by a study employing acoustic reflection measurements, which revealed that upper airway dimensions decreased with age, male sex and supine position. ${ }^{16}$

The association between short neck, obesity, missing maxillary incisors and protruding teeth as predictors of difficult intubation in obstetric patients has been analyzed by Rocke et al. ${ }^{12}$ Univariate analysis revealed a significant association between difficult intubation and obesity, short neck, and problems with the upper teeth, while multivariable analysis removed obesity as a risk factor because of its association with short neck.
We found that morbid obesity is a predictor of DL (Table III). Also apparently controversial, our study shows that being morbidly obese carries the risk of DL, but surprisingly not because of an increase in BMI per se. This means that other factors associated with obesity might have an impact on layngoscopic difficulty. To find out which factor might have been associated with morbid obesity we searched for significant interactions between various pairs of independent predictors (Table III). A statistically significant interaction was noted between obesity and abnormal upper teeth. Also, the incidence of OSA in the study group was higher ( $10 \%$ vs $1 \%)$ and grade III laryngoscopy was very frequent in patients suffering from OSA and belonging to the study group (18 out of the 24 patients with a grade III laryngoscopy in the study group had a history of OSA).

We speculate that the distribution pattern of body fat rather than the BMI itself may be more relevant for rendering the laryngoscopy more difficult. By using magnetic resonance imaging measurements in obese patients with and without obstructive sleep apnea, Horner et al. ${ }^{17}$ demonstrated that more fat was present in areas surrounding the collapsible segments of the pharynx in patients with OSA. This may explain why some obese patients are easy to intubate/ventilate, while others are not. Furthermore, difficult intubation had been significantly associated with OSA. ${ }^{18}$

Hoffstein $^{19}$ and Mortimore ${ }^{20}$ have demonstrated that patients with OSA have fatter necks than equally obese patients without OSA. The $28 \%$ increase in neck soft tissue volume - neck "mass loading" 20 may be responsible for the difficult laryngoscopic view and more collapsible airway resulting in difficult intubation/ventilation in obese patients with thick ("bull") necks and OSA. The higher incidence of difficult airway in males may be related to the higher percentage of neck soft tissue (and fat) in males compared to women. ${ }^{21}$ While the laryngoscopy difficulty seems to be similar in both the obese and non-obese populations, the incidence of difficult mask ventilation is definitely higher in obese patients. ${ }^{22}$

We conclude that BMI per se has no influence on the difficulty of laryngoscopy.

\section{References}

1 Ochroch EA, Hollander JE, Kush S, Shofer FS, Levitan $R M$. Assessment of laryngeal view: percentage of glottic opening score vs Cormack and Lehane grading. Can J Anesth 1999; 46: 987-90.

2 Cormack R, Lebane J. Difficult tracheal intubation in obstetrics. Anaesthesia 1984; 39: 1105-11.

3 Karkouti K, Rose DK, Ferris L, Wigglesworth D, 
Meisami-Fard T, Lee H. Inter-observer reliability of ten tests used for predicting difficult tracheal intubation. Can J Anaesth 1996; 43: 554-9.

4 Voyagis G, Kyriakis K, Dimitrion V, Vrettou I. Value of oropharyngeal Mallampati classification in predicting difficult laryngoscopy among obese patients. Eur J Anaesthesiol 1998; 15: 330-4.

5 Bond $A$. Obesity and difficult intubation. Anaesth Intensive Care 1993; 21: 828-30.

6 McCarren JP. Respiratory diseases. In: Benumof JL (Ed.). Anesthesia and Uncommon Diseases, $4^{\text {th }} \mathrm{ed}$. Philadelphia: W.B. Saunders; 1998: 65-6.

7 Vaughan RS. Predicting a difficult intubation. In: Latto IP, Vaughan RS (Eds.). Difficulties in Tracheal Intubation, $2^{\text {nd }}$ ed. London: W.B. Saunders; 1997: 80-1.

8 Samsoon GL, Young JR. Difficult tracheal intubation: a retrospective study. Anaesthesia 1987; 42: 487-90.

9 Horton WA, Faby L, Charters P. Defining a standard intubation position using "angle finder". Br J Anaesth 1989; 62: 6-12.

10 Rosenbaum S, Skinner RK, Knight IB, Garrow JS. A survey of heights and weights in Great Britain, 1980. Ann Hum Biol 1985; 12: 115-27.

11 Abraham S, Johnson CL. Prevalence of severe obesity in adults in the United States. Am J Clin Nutr 1980; 33S: 364-9.

12 Rocke DA, Murray WB, Rout CC, Gouws E. Relative risk analysis of factors associated with difficult intubation in obstetric anesthesia. Anesthesiology 1992; 77 : 67-73.

13 Meyer RJ. Obesity and difficult intubation. Anaesth Intensive Care 1994; 22: 314-5.

14 Wilson $M$. Predicting difficult intubation (Editorial). $\mathrm{Br}$ J Anaesth 1993; 71: 333-4.

15 Rose DK, Cohen MM. The incidence of airway problems depends on the definition used. Can J Anaesth 1996; 43: 30-4.

16 Martin SE, Mathur R, Marshall I, Douglas NJ. The effect of age, sex, obesity and posture on upper airway size. Eur Respir J 1997; 10: 2087-90.

17 Horner RL, Mohiaddin RH, Lowell DG, et al. Sites and sizes of fat deposits around the pharynx in obese patients with obstructive sleep apnoea and weight matched controls. Eur Respir J 1989; 2: 613-22.

18 Hiremath AS, Hillman DR, James AL, Noffsinger WJ, Platt PR, Singer SL. Relationship between difficult tracheal intubation and obstructive sleep apnoea. $\mathrm{Br} \mathrm{J}$ Anaesth 1998; 80: 606-11.

19 Hoffstein V, Mateika S. Differences in abdominal and neck circumferences in patients with and without obstructive sleep apnoea. Eur Respir J 1992; 5 : 377-81.
20 Mortimore IL, Marshall I, Wraith PK, Sellar RJ, Douglas NJ. Neck and total body fat deposition in nonobese and obese patients with sleep apnea compared with that in control subjects. Am J Resp Crit Care Med 1998; 157: 280-3.

21 Whittle AT, Marshall I, Mortimore IL, Wraith PK, Sellar RJ, Douglas NJ. Neck soft tissue and fat distribution: comparison between normal men and women by magnetic resonance imaging. Thorax 1999; 54: 323-8.

22 Langeron $O$, Masso E, Huraux $C$, et al. Prediction of difficult mask ventilation. Anesthesiology 2000; 92: 1229-36. 